\title{
Infusão endovenosa domiciliar: tecnologias educativas para 0 cuidado à pessoa com hemofilia
}

\author{
Home intravenous infusion: educational technologies for the care of people with hemophilia \\ Infusión intravenosa domiciliaria: tecnologías educativas para el cuidado de personas con hemofilia
}

Carla Renata da Silva Pacheco ${ }^{1}$ (i) https://orcid.org/0000-0002-2979-4049

Cândida Caniçali Primo ${ }^{1}$ ic https://orcid.org/0000-0001-5141-2898

Mirian Fioresi ${ }^{1}$ (D) https://orcid.org/0000-0002-8560-4385

Carlos Alberto da Cruz Sequeira² ${ }^{2}$ https://orcid.org/0000-0002-5620-3478

Luciana de Cássia Nunes Nascimento ${ }^{1}$ ib https://orcid.org/0000-0003-4947-5480

Andressa Bolsoni Lopes ${ }^{1}$ id https://orcid.org/0000-0003-1244-5667

Walckiria Garcia Romero Sipolatti1 io https://orcid.org/0000-0002-1365-4797

Como citar: CA, Nascimento LC, Lopes AB, et al. Infusão endovenosa domiciliar: tecnologias educativas para 0 cuidado à pessoa com hemofilia. Acta Paul Enferm. 2022;35:eAPE02902.

DOI

http://dx.doi.org/10.37689/acta-ape/2022A002902

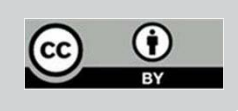

Descritores

Tecnologia educacional; Hemofilia A; Administração intravenosa; Assistência domiciliar; Materiais de ensino

Keywords

Educational technology; Hemophilia A; Administration, intravenous; Home nursing; Teaching materials

\section{Descriptores}

Tecnología educacional; Hemofilia A; Administración intravenosa; Atención domiciliaria de salud; Materiales de enseñanza

Submetido 3 de Outubro de 2020 Aceito 26 de Maio de 2021

\section{Autor correspondente} Carla Renata da Silva Pacheco E-mail: carla-uff@hotmail.com/ carlauff01@gmail.com

Editor Associado (Avaliação pelos pares): Camila Takao Lopes
(https://orcid.org/0000-0002-6243-6497) Escola Paulista de Enfermagem, Universidade Federal de São Paulo, São Paulo, SP, Brasil

\section{Resumo}

Objetivo: Elaborar e validar tecnologias educativas para o cuidado domiciliar de pessoas com hemofilia em infusão endovenosa do fator de coagulação.

Método: Estudo metodológico, desenvolvido em três etapas: elaboração de tecnologias educativas, avaliação de conteúdo e aparência por juízes e apreciação por pessoas com hemofilia. As tecnologias educativas cartilha e infográfico - foram elaboradas mediante revisão de literatura. Na etapa de avaliação com juízes, foi utilizada a técnica Delphi em duas rodadas, por meio do Índice de Validade de Conteúdo, concordância superior a 0,80 em relação a clareza de linguagem, pertinência prática e relevância teórica. Na avaliação com o público-alvo, foi considerado o nível de concordância de respostas positivas maior ou igual a $80 \%$ nos itens de organização, o estilo de escrita, a aparência e a motivação para a leitura.

Resultados: A cartilha apresentou índice de validade de conteúdo global de 0,88 na primeira rodada e 0,98 na segunda; e 0 infográfico, 0,88 na primeira rodada e 0,97 na segunda. Na apreciação das tecnologias educativas pelo público-alvo, o nível de concordância das respostas positivas foi superior a $80 \%$.

Conclusão: Este estudo elaborou tecnologias educativas, cartilha e infográfico, que poderão contribuir com a adesão ao tratamento e promoção do cuidado, por meio de padronização das orientações às pessoas com hemofilia em infusão endovenosa domiciliar.

\section{Abstract}

Objective: To develop and validate educational technologies for home care of people with hemophilia on intravenous infusion of clotting factor.

Method: This is a methodological study, developed in three stages: development of educational technologies, content and appearance assessment by judges, and appraisal by people with hemophilia. The educational technologies - a booklet and an infographic - were developed through a literature review. In the assessment stage with judges, the Delphi technique was used in two rounds, through Content Validity Index, agreement greater than 0.80 in regarding clarity of language, practical relevance, and theoretical relevance. In the assessment with the target audience, the level of agreement of positive responses greater than or equal to $80 \%$ in the items of organization, writing style, appearance and motivation for reading was considered.

Results: The booklet presented a global content validity index of 0.88 in the first round and 0.98 in the second; and the infographic, 0.88 in the first round and 0.97 in the second. In the assessment of educational technologies by the target audience, the level of agreement of positive responses was higher than $80 \%$. 
Conclusion: This study developed educational technologies, a booklet and an infographic, which could contribute to adherence to treatment and promotion of care, by standardizing the guidelines for people with hemophilia in intravenous infusion at home.

\section{Resumen}

Objetivo: Elaborar y validar tecnologías educativas para el cuidado domiciliario de personas con hemofilia sobre la infusión intravenosa domiciliaria del factor de coagulación.

Métodos: Estudio metodológico desarrollado en tres etapas: elaboración de tecnologías educativas, evaluación de contenido y apariencia por jueces y valoración por parte de personas con hemofilia. Las tecnologías educativas (cartilla e infográfico) fueron elaboradas mediate revisión de literatura. En la etapa de evaluación con jueces, se utilizó el método Delphi en dos rondas, por medio del Índice de Validez de Contenido, concordancia superior a 0,80 con relación a la claridad del lenguaje, pertinencia práctica y relevancia teórica. En la evaluación con el público destinatario, se consideró el nivel de concordancia de respuestas positivas mayor 0 igual a $80 \%$ en los ítems organización, estilo de escritura, apariencia y motivación para lectura.

Resultados: La cartilla presentó un Índice de Validez de Contenido global de 0,88 en la primera ronda y 0,98 en la segunda. El infográfico presentó 0,88 en la primaria ronda y 0,97 en la segunda. En la valoración de las tecnologías educativas por el público destinatario, el nivel de concordancia de las respuestas positivas fue superior al $80 \%$.

Conclusión: En este estudio se elaboraron tecnologías educativas, cartilla e infográfico, que podrán contribuir con la adherencia al tratamiento y promoción del cuidado, mediante la estandarización de las instrucciones a personas con hemofilia sobre infusión intravenosa domiciliaria.

\section{Introdução}

A hemofilia é uma doença hemorrágica ligada ao cromossomo $\mathrm{X}$, caracterizada pela deficiência ou ausência do fator de coagulação VIII (hemofilia A) ou IX (hemofilia B). ${ }^{(1)} \mathrm{A}$ apresentação clínica das hemofilias A e B é semelhante, pois ambas são caracterizadas por sangramentos intra-articulares (hemartroses), hemorragias nos músculos, nas cavidades ou em outros tecidos. $\mathrm{O}$ tratamento terapêutico fundamenta-se na administração dos fatores de coagulação VIII ou IX, podendo ocorrer sob demanda (logo após um sangramento) ou profilático. Devido à impossibilidade de se manterem níveis constantes de fatores de coagulação nas pessoas com hemofilia, esses indivíduos vivem sob a constante ameaça de sangramento inesperado. ${ }^{(2)}$

Dessa forma, o Programa Nacional de Coagulopatias Hereditárias prevê a autoinfusão endovenosa pela própria pessoa com hemofilia - ou pelo familiar - todas as vezes que houver suspeita de sangramentos, de trauma ou necessidade de infundir o fator de coagulação, de forma profilática. ${ }^{(3)}$ Para tal, a pessoa com hemofilia deve estar cadastrada em um centro de tratamento especializado, participar de reunião de esclarecimento sobre a inserção no tratamento domiciliar e dos treinamentos, a fim de aprender a aplicar o concentrado de fator por via endovenosa, bem como estar com exames laboratoriais e clínicos atualizados. ${ }^{(4)}$

Para auxiliar a prática do enfermeiro, o Guidelines for the Management of Hemophilia aborda o conteúdo do treinamento de infusão domiciliar, direcionado ao conhecimento geral sobre a doença: identificação de hemorragias; medidas de primeiros socorros; reconstituição do fator de coagulação; técnicas assépticas para se realizar da punção; registros no diário de infusão; e armazenamento adequado das agulhas e de objetos perfurocortantes. ${ }^{(5-7)}$

Nesse contexto, é responsabilidade do enfermeiro a prestação de informações sobre a assistência de enfermagem, os riscos e as complicaçóes durante o tratamento à pessoa com hemofilia, ao familiar ou ao cuidador. ${ }^{(8)}$ No entanto, há a necessidade de padronização de informaçóes, bem como a utilização de materiais educativos que auxiliem nesse cuidado. (9) Os estudos sobre programas educacionais domiciliares para esse público-alvo são limitados. Embora existam materiais educativos sobre o tema, poucos são validados. ${ }^{(10)}$

Sabe-se que o uso de tecnologias educacionais impressas proporciona o desenvolvimento de habilidades e media os conhecimentos durante as açóes educativas. É uma alternativa viável para informar e sensibilizar a população, que contribui para promover a saúde por meio da participaçáo popular, em uma construção compartilhada de conhecimentos. Além disso, permite ao paciente e à sua família uma leitura posterior, que reforça as orientaçóes verbais realizadas na consulta de enfermagem, servindo como guia em casos de dúvidas e auxiliando nas tomadas de decisão cotidianas. ${ }^{(11)}$

Nesse cenário, considerando que a prática incorreta do procedimento de infusão domiciliar en- 
dovenosa representa riscos para a saúde, bem como implicações na qualidade de vida, altos custos à saúde pública - e que a falta de materiais educativos dificulta a prestação de informaçóes adequadas -, o estudo justifica-se por desenvolver materiais educativos direcionados ao cuidado de pessoas com hemofilia. Logo, o objetivo foi elaborar e avaliar tecnologias educativas para o cuidado domiciliar de pessoas com hemofilia em infusão endovenosa do fator de coagulação.

\section{Métodos}

Trata-se de estudo metodológico, realizado no período de março de 2017 a abril de 2019, desenvolvido em três etapas: elaboração das tecnologias educativas, em formato de cartilha e infográfico; avaliação de conteúdo pelos juízes; e apreciação pelo público-alvo. As tecnologias educativas produzidas neste estudo são destinadas a pessoas com hemofilia que fazem terapia de infusão endovenosa do fator de coagulação em domicílio.

A elaboração das tecnologias foi iniciada com o levantamento bibliográfico, por meio de revisão de literatura, utilizando as seguintes fontes: Diretrizes internacionais da World Federation of Homophilia (Guidelines for the Management of Hemophilia) e recomendaçôes do Ministério da Saúde. ${ }^{(3,5,12,13)}$

O referencial metodológico, para a elaboração da cartilha educativa, seguiu as orientaçóes de Moreira, Nóbrega e Silva, os preceitos de Echer e Diretrizes de $A$ Guide to Creating and Evaluating Patient Materials. ${ }^{(14,16)}$ Quanto ao Infográfico, o referencial metodológico seguiu as orientaçóes de Moreira, Nóbrega e Silva e de Carvalho e Aragão. $(14,17)$ Após elencar o conteúdo pertinente para os materiais, preparou-se o roteiro com informaçóes e textos e, posteriormente, adequação da linguagem científica. Em sequência, com auxílio de designer gráfico, foi elaborada a arte, por meio da confecção de ilustrações, configuração e diagramação das páginas.

A segunda etapa, denominada avaliação de conteúdo e aparência, foi realizada com o intuito de verificar se a exposição dos conceitos ocorreu de maneira adequada, e se os textos do instrumento foram representativos dentro do universo do produto. ${ }^{(18)}$ Optou-se por utilizar a técnica Delphi, que consiste em um método sistematizado de julgamento de informaçóes para obter consenso entre os juízes em relação a determinado tema, por meio da aplicação de questionários estruturados e da realização de feedback estatístico de cada ciclo. (19) Neste estudo, a utilização da técnica Delphi ocorreu em duas rodadas: a primeira consistiu no envio inicial das tecnologias educativas aos juízes, no mês de fevereiro de 2018; e a segunda, ao reenvio após adequações feitas a partir das sugestóes da primeira rodada, no mês de junho de 2018.

A escolha dos juízes foi realizada de acordo com os seguintes critérios de inclusão: ser enfermeiro com titulação mínima de especialista e possuir experiência clínica de, no mínimo, dois anos experiência na área de hemofilia. A busca pelos juízes ocorreu por amostragem intencional tipo snowball. (20) Assim, quando um juiz se enquadrava nos critérios de elegibilidade preestabelecidos, solicitava-se que ele indicasse outros possíveis participantes, tratando-se, portanto, de uma amostragem por conveniência. Nesse sentido, 34 juízes foram contatados via correio eletrônico, por meio de uma carta-convite, dentre os quais 11 aceitaram participar da primeira rodada do estudo por meio da devolução do material, dentro do prazo estipulado de 15 dias. $\mathrm{Na}$ segunda rodada, esses 11 juízes receberam novamente o material com as modificaçóes sugeridas; porém, apenas 7 devolveram o material dentro do prazo estipulado de 15 dias, Os quatro juízes que não puderam participar da segunda rodada do estudo alegaram indisponibilidade de tempo.

Após a anuência para participar da pesquisa, foram entregues aos juízes: instruçóes para operacionalização; Termo de Consentimento Livre e Esclarecido; instrumento de validação, juntamente com a cartilha educativa e infográfico nas versôes digitalizadas.

Os juízes avaliaram a cartilha e o infográfico, respondendo a um instrumento contendo questóes referentes à sua caracterização e um instrumento adaptado de Leite e Crestani, composto por duas partes: a primeira continha itens relacionados à análise dos 
objetivos, da estrutura, da apresentação e da relevância das tecnologias educativas produzidas; a segunda parte era composta por itens que avaliaram todos os assuntos ali presentes de forma minuciosa. Para essa avaliação, utilizou-se a escala tipo Likert, com quatro pontos, variando de "nada pertinente" a "muitíssimo pertinente", a qual permite avaliar cada subtítulo da cartilha e do infográfico a partir da clareza de linguagem, pertinência prática e relevância teórica. Quanto às opçóes assinaladas como "nada" e "pouco pertinente", foram solicitadas justificativas e, posteriormente, revisados os itens pelas pesquisadoras. ${ }^{(21,22)}$

$\mathrm{Na}$ análise do instrumento de avaliação pelos juízes, o cálculo baseou-se no Índice de Validação de Conteúdo (IVC), adotando-se como desejável o IVC maior que 0,80. ${ }^{(23)}$ Aqueles que apresentaram IVC menores que 0,80 poderiam ser excluídos ou modificados, de acordo com a sugestão dos juízes. O escore do IVC foi calculado por meio da soma de concordância dos itens marcado como 3 ou 4, dividida pelo número total de respostas. Para avaliação completa da cartilha e infográfico, utilizou-se o somatório de todos os IVC calculados separadamente, dividindo-os pelo número de itens do instrumento. ${ }^{(18)}$ Os dados foram analisados e fundamentados na literatura pertinente sobre o assunto.

A terceira etapa ocorreu mediante apreciação das tecnologias educativas pelo público-alvo, no mês de janeiro de 2019. Participaram dessa etapa todas as pessoas com hemofilia $\mathrm{A}$ e $\mathrm{B}$ ou pais/responsáveis de crianças com hemofilia que faziam terapia de infusão endovenosa em domicílio, e estavam aguardando consulta na sala de espera do ambulatório de um Centro de Hematologia, referência para o atendimento de coagulopatias na região Sudeste. Cumpre destacar que todas as pessoas com hemofilia em uso do fator de coagulação em domicílio recebem treinamentos para a realização de infusão endovenosa.

Adotaram-se os seguintes critérios de inclusão: possuir idade igual ou superior a 18 anos, ser cadastrado no programa de coagulopatias da instituição, ser alfabetizado e náo possuir vínculo de relacionamento com a pesquisadora. $\mathrm{O}$ critério de exclusão adotado foi: apresentar deformidade em membros superiores, ocasionados por artropatia hemofílica crônica, que inviabilizassem a avaliação dos mate- riais. Cumpre ressaltar que não houve participantes excluídos nessa seleção intencional.

O público-alvo que participou da pesquisa assinou o Termo de Consentimento Livre e Esclarecido, recebeu a cartilha e o infográfico impressos, juntamente com um instrumento composto de itens que consideravam os domínios de organização, o estilo de escrita, a aparência e a motivação. ${ }^{(23,24)}$

O participante foi direcionado individualmente a uma sala reservada, a fim de iniciar a leitura dos materiais. Em seguida, eles responderam os instrumentos que continham respostas do tipo "sim", "não" e "não sei". Durante todo o período, a pesquisadora colocou-se à disposição para esclarecer as eventuais dúvidas quanto ao preenchimento da avaliação.

Por fim, as tecnologias educativas foram avaliadas por dois professores do Curso de Línguas e um pedagogo do Curso de Educação, de uma universidade pública, para a revisão gramatical e textual.

$\mathrm{Na}$ análise dos dados julgados pelo público-alvo, consideram-se os itens com nível de concordância igual ou superior a $80 \%$ de respostas positivas; ou seja, aquelas que obtiveram "sim". Os itens com índice de concordância menor que $80 \%$ foram considerados dignos de alteração.

Os dados foram compilados em uma planilha do programa Microsoft Office 365 e, após codificação e tabulação, analisados por meio de estatística descritiva.

O estudo foi aprovado pelo Comitê de Ética em Pesquisa da Universidade Federal do Espírito Santo, sob Parecer n.o 2.428.681, obedecendo à Resoluçáo n. ${ }^{\circ}$ 466/2012 (CAAE: 79412117.8.0000.5060).

\section{Resultados}

Os resultados estão apresentados em três etapas distintas: elaboração das tecnologias, avaliação pelos juízes e avaliação pelo público-alvo.

\section{Elaboração da cartilha e infográfico}

A versão inicial da cartilha foi composta por 28 páginas, tamanho A4 (210 x 297), intitulada "Aplicando o fator de coagulação em domicílio", e dividida em 17 subtítulos. 
Após a avaliação pelos juízes e apreciação pelo público-alvo, a versão final da cartilha foi intitulada "Aplicando o fator de coagulação em domicílio na pessoa com hemofilia", possuindo 28 páginas, com dimensão de $150 \times 210 \mathrm{~mm}$, impressa colorida no papel couchê fosco de $150 \mathrm{~g} / \mathrm{m} 2$. O conteúdo foi sumarizado em 17 subtítulos. Na figura 1, são apresentadas algumas páginas da cartilha.

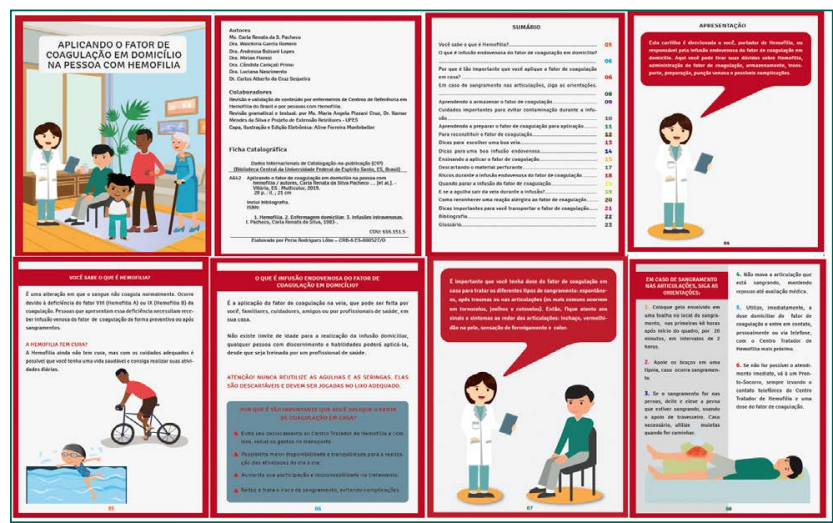

Figura 1. Páginas da versão final da cartilha "Aplicando o fator de coagulação em domicílio na pessoa com hemofilia"

A versão inicial do infográfico foi composta por 14 orientaçóes, em sequência numerada, do tipo passo a passo, para a infusão domiciliar do fator de coagulação, distribuídas próximas às margens do material. Para facilitar a leitura e garantir a segurança durante a preparação da medicação, foi destinado um espaço em branco no centro do infográfico, com as seguintes mediçôes: $47 \mathrm{~cm}$ horizontal e 35 $\mathrm{cm}$ vertical. Após a construção do texto e seleção das figuras correspondentes, foi enviado para a diagramação pela designer gráfica.

A versão final do infográfico manteve-se com as formataçóes iniciais, contendo as 14 orientaçóes do tipo passo a passo. No entanto, foram inseridas as recomendações dos juízes e das pessoas com hemofilia para aperfeiçoamento da tecnologia educativa.

O infográfico denominado "Campo de autoinfusão" constitui-se de material Policloreto de Vinil (PVC) impresso revestido, permitindo ser limpo com desinfetantes sem danificar as imagens e textos. Apresenta as orientaçóes dispostas próximas às margens do material, em sequência numerada, possuindo as mesmas mediçóes iniciais. A figura 2 representa a versão final após avaliação.

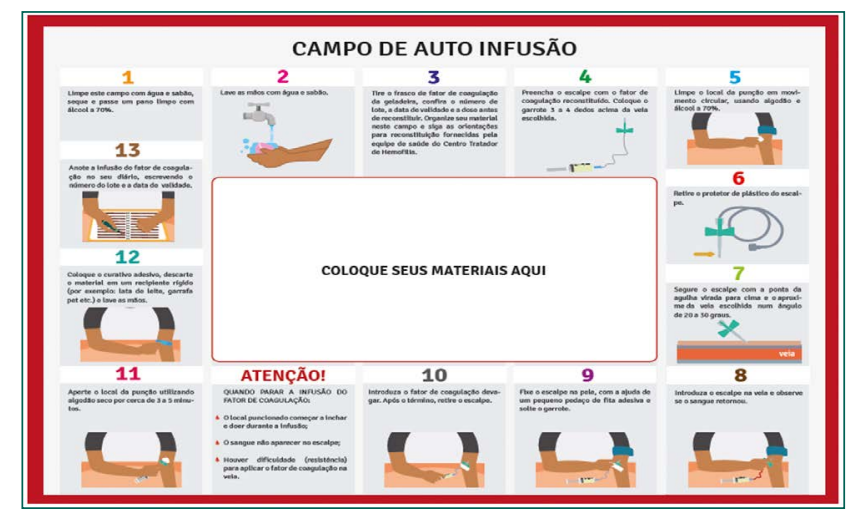

Figura 2. Versão final validada do infográfico "Campo de autoinfusão"

\section{Avaliação pelos juízes}

A avaliação foi realizada por 11 enfermeiras, na primeira rodada da técnica Delphi. Apresentavam, predominantemente, idades entre 31 e 40 anos $(54,5 \%)$. Dentre elas, duas doutoras $(18,2 \%)$, três mestres $(27,3 \%)$ e seis especialistas $(54,5 \%)$. Com relação ao exercício profissional, 4 possuíam tempo de término de graduação entre 1 e 10 anos (36,3\%), 3 entre 11 e 20 anos (27,3\%), duas entre 21 e 30 anos (18,2\%) e duas entre 31 e 40 anos (18,2\%). Quanto ao tempo de experiência em hemofilia, seis juízes possuíam entre dois e cinco anos (54,5\%).

Para a segunda rodada, participaram sete juízes (63\%), sendo classificados em: idades entre 31 e 40 anos $(57,1 \%)$, e todas eram do sexo feminino (100\%). Dentre elas, 2 mestres $(28,6 \%)$ e cinco especialistas $(71,4 \%)$. Com relação ao exercício profissional, 3 possuíam tempo de término de graduação entre 1 e 10 anos (42,8\%), 3 entre 11 e 20 anos $(42,8 \%)$ e 1 entre 21 e 30 anos (14,2\%). Quanto ao tempo de experiência em hemofilia, 6 possuíam entre 2 e 5 anos (85,7\%), e 1 acima de 11 anos (14,3\%).

Na primeira rodada, 4 dos 17 subtítulos da primeira versão da cartilha apresentaram IVC inferior a 0,80 em relação à clareza de linguagem, pertinência prática e relevância teórica. Assim, foram realizadas 12 sugestôes para substituição ou exclusão de termos, reformulação de ilustração, readequação de frases, dentre outros. Essas propostas foram analisadas e todas as sugestóes acatadas com base na literatura científica pertinente. Apesar de alguns subtítulos apresentarem IVC maior que 0,80 , efetuaram-se 34 consideraçóes pelos juízes - como sugestóes para readequação de fra- 
ses -, sendo 24 acatadas pelas pesquisadoras. Após as adequaçôes, reenviaram-se os materiais e, na segunda rodada, todos os IVCs foram maiores que 0,80 , e somente um juiz realizou nova sugestão.

$\mathrm{Na}$ avaliação do infográfico, das 14 orientações analisadas individualmente quanto à clareza de linguagem, à pertinência prática e à relevância teórica, cinco apresentaram IVC menor que 0,80 , nas quais foram realizadas sete sugestóes de adequaçóes pelos juízes. Após as alterações, o infográfico foi reenviado e, na segunda rodada, apresentou IVC maior que 0,80 nas avaliaçóes individuais, sem novas sugestóes.

Ao compararmos os IVCs da primeira e segunda rodadas da avaliação da cartilha, verificamos que, em relação ao objetivo, todos os itens obtiveram IVC maior que 0,80. No infográfico, entretanto, apenas um item apresentou IVC menor que 0,80 na primeira rodada. Quanto à estrutura e à apresentação, o IVC foi de 0,72 em dois tópicos apresentados, e no infográfico, um tópico. Em relação à relevância, todos os itens da cartilha e infográfico obtiveram IVC maior que 0,80 nas duas rodadas, conforme a tabela 1 .

Tabela 1. Avaliação dos juízes quanto aos objetivos, à estrutura/apresentação, à relevância e IVC da cartilha e do infográfico por item, na primeira e na segunda rodadas da técnica Delphi

\begin{tabular}{|c|c|c|c|c|}
\hline \multirow[b]{2}{*}{ Itens } & \multicolumn{2}{|c|}{ Cartilha } & \multicolumn{2}{|c|}{ Infográfico } \\
\hline & $\begin{array}{c}1 .^{\mathrm{a}} \\
\text { Rodada } \\
\mathrm{n}=11 \\
\text { IVC }\end{array}$ & $\begin{array}{c}2^{\mathrm{a}} \\
\text { Rodada } \\
\mathrm{n}=7 \\
\text { IVC }\end{array}$ & $\begin{array}{c}1 .^{\mathrm{a}} \\
\text { Rodada } \\
\mathrm{n}=11 \\
\text { IVC }\end{array}$ & $\begin{array}{c}2 .^{\mathrm{a}} \\
\text { Rodada } \\
\mathrm{n}=7 \\
\text { IVC }\end{array}$ \\
\hline \multicolumn{5}{|l|}{ 1. Objetivos } \\
\hline 1.1 Contempla o tema proposto & 1,00 & 0,85 & 0,72 & 0,85 \\
\hline $\begin{array}{l}1.2 \text { Adequado ao processo de ensino- } \\
\text { aprendizagem }\end{array}$ & 0,90 & 0,85 & 0,81 & 0,85 \\
\hline 1.3 Esclarece dúvidas sobre o tema abordado & 1,00 & 1,00 & 1,00 & 1,00 \\
\hline 1.4 Proporciona reflexão sobre o tema & 0,90 & 1,00 & 1,00 & 1,00 \\
\hline 1.5 Incentiva mudança de comportamento & 1,00 & 1,00 & 1,00 & 1,00 \\
\hline \multicolumn{5}{|l|}{ 2. Estrutura e Apresentação } \\
\hline 2.1 Linguagem adequada ao público-alvo & 1,00 & 1,00 & 1,00 & 1,00 \\
\hline $\begin{array}{l}2.2 \text { Linguagem interativa, permitindo } 0 \\
\text { envolvimento ativo no processo educativo }\end{array}$ & 1,00 & 1,00 & 1,00 & 1,00 \\
\hline 2.3 Informações corretas & 0,72 & 0,85 & 1,00 & 1,00 \\
\hline 2.4 Informações objetivas e esclarecedoras & 0,72 & 0,85 & 0,81 & 0,85 \\
\hline 2.5 Informações necessárias & 1,00 & 1,00 & 1,00 & 1,00 \\
\hline 2.6 Sequência lógica das ideias & 0,90 & 0,85 & 0,72 & 1,00 \\
\hline 2.7 Tema atual & 1,00 & 1,00 & 1,00 & 1,00 \\
\hline 2.8 Tamanho do texto adequado & 1,00 & 1,00 & 1,00 & 1,00 \\
\hline \multicolumn{5}{|l|}{ 3. Relevância } \\
\hline 3.1 Estimula 0 aprendizado & 1,00 & 1,00 & 0,90 & 1,00 \\
\hline 3.2 Contribui para o conhecimento na área & 0,90 & 1,00 & 0,90 & 0,85 \\
\hline 3.3 Desperta interesse pelo tema & 0,90 & 1,00 & 0,90 & 1,00 \\
\hline
\end{tabular}

n - número de juízes; IVC - Índice de Validade de Conteúdo

\section{Apreciação pelo público-alvo}

Os materiais foram apreciados pelo público-alvo, representado por 10 pessoas com hemofilia, faixa etária entre 33 e 52 anos, sendo 8 do sexo masculino e 2 do sexo feminino. Em relação ao nível de escolaridade, $1(10 \%)$ possui ensino fundamental incompleto, outro (10\%) fundamental completo, 4 (40\%) ensino médio completo, 2 (20\%) ensino superior completo, 1 (10\%) especialização e outro (10\%) doutorado.

Para a apreciação da cartilha, dos quatro domínios avaliados, o estilo de escrita, a aparência e a motivação obtiveram maior número de respostas positivas. O nível de concordância das respostas positivas variou de $90 \%$ a $100 \%$ entre os itens abordados, totalizando 99,2\%, de forma geral. No entanto, foram feitas oito sugestóes em relação à organização, ao estilo de escrita e à aparência, sendo sete acatadas e incluídas na versão final da cartilha.

Para a apreciação do infográfico, utilizou-se o mesmo instrumento de avaliação de aparência da cartilha. Dos quatro domínios avaliados - organização, estilo de escrita, aparência e motivação -, todos apresentaram nível de concordância maior que $80 \%$ nas respostas positivas, e apenas uma sugestão.

\section{Discussão}

Esta pesquisa promoveu a elaboração e a avaliação de conteúdo e aparência de duas tecnologias educativas, que servirão para as pessoas com hemofilia, cuidadores e familiares sanarem dúvidas e superarem dificuldades no contexto domiciliar da infusão endovenosa do fator de coagulação. Ou seja, contribuirá para agir positivamente no processo saúde-doença, prevenindo complicaçóes e reduzindo os custos relacionados ao uso incorreto dessa medicação.

Apesar dos avanços nos meios de comunicação eletrônicos, optou-se pela confecção de materiais escritos. Tal escolha justifica-se pelo fato de serem materiais de fácil acesso, sem a necessidade de tecnologia, o que contribui para a orientação da população em geral, independentemente de seu nível socioeconômico. 
A intenção da cartilha, intitulada "Aplicando o fator de coagulação em domicílio na pessoa com hemofilia", e do infográfico, intitulado "Campo de autoinfusão", é propiciar a construção do conhecimento da pessoa com hemofilia por meio de uma aprendizagem significativa, capaz de promover mudanças reais de atitudes. Além disso, a proposta da elaboração do infográfico é orientar passo a passo, de forma guiada e resumida, como suporte físico para os materiais utilizados durante a realização da infusão endovenosa domiciliar.

Por essa razão, o enfermeiro, ao realizar suas orientaçóes, pode se apropriar de ferramentas tecnológicas para se comunicar com o paciente e estimular seu interesse no aprendizado, em que a utilização de cartilhas educativas possa integrar os pacientes no processo de ensino-aprendizagem, tornando-os potenciais mediadores e protagonistas no ato de cuidar. ${ }^{(25,26)}$ Nesse contexto, tanto a cartilha como o infográfico, produzidos neste estudo, podem desenvolver comportamentos positivos e aumentar a adesão à profilaxia, além de prevenir o agravamento dos eventos adversos.

No processo de avaliação de conteúdo e aparência das tecnologias educativas, foram incluídas as contribuições dos juízes e apreciação pelos representantes do público-alvo. Apesar de o IVC global ter sido satisfatório na primeira e segunda rodadas, os juízes realizaram sugestôes, visando garantir a melhor qualidade dos materiais educativos. Tais detalhes contribuem para o enriquecimento do produto final e o aprimoramento de sua aplicabilidade. ${ }^{(27,28)}$

Sendo assim, o processo de adaptação do material educativo às sugestóes dos juízes é uma etapa essencial para tornar a tecnologia mais completa e com maior rigor científico. $\mathrm{Na}$ avaliação da cartilha, três juízes enfatizaram a necessidade de trocar as figuras ilustrativas do subtítulo "Você sabe o que é Hemofilia?". As modificações na cartilha foram orientadas de acordo com as Diretrizes Internacionais, as indicam que as práticas de esportes de baixo impacto, como natação, ciclismo e dança são mais recomendadas. Outra alteração de ilustração foi relacionada ao subtítulo "Descartando o material perfurocortante", pois um juiz recomendou a troca do símbolo do recipiente reciclável para o símbolo infectante, representando, assim, material de risco biológico. ${ }^{(5,29)}$

Sugeriram-se também acréscimos de informaçôes relevantes e melhoria na escrita dos tópicos relacionados aos benefícios da infusão em domicílio: as orientaçóes em caso de sangramento articular; os cuidados para evitar infecção durante a infusão; a aplicação do fator de coagulação; o reconhecimento de reação alérgica; e algumas dicas para transportar o fator de coagulação. Vale salientar que as alteraçôes foram acatadas devido à concordância técnica e à pertinência na literatura científica.

Em relação à avaliação de conteúdo e aparência do infográfico, dois juízes sugeriram incluir ilustração para demonstrar a angulação do escalpe sendo introduzido na veia. Visando facilitar a compreensão, inseriu-se uma figura representativa, seguindo as orientaçôes de punção venosa do Ministério da Saúde. ${ }^{(12,13)}$

O público-alvo também apreciou as tecnologias educativas de forma positiva, e as considerou importantes para a promoção do conhecimento, com um conteúdo rico aliado à clareza, ao formato adequado e às ilustraçóes explicativas. Tais resultados devem-se ao fato de a terapia domiciliar diminuir os números de faltas na escola e no trabalho, aumentar a liberdade para a realização de atividades de lazer, bem como promover maior responsabilidade do paciente em relação ao próprio tratamento e menor tempo de dor. Além de reduzir as suas visitas ao Centro Tratador. ${ }^{(30)}$

Assim, foi possível observar o nível de concordância das respostas positivas entre $90 \%$ a $100 \%$ na avaliação da cartilha. Das oito sugestóes relacionadas a acréscimos de informações, substituição de termos técnicos e correçóes na sequência numérica de tópicos, sete foram acatadas. Considerando que a autoinfusão endovenosa pela pessoa com hemofilia ou pelo familiar está condicionada à participação em treinamentos, ${ }^{(4)}$ as sugestóes de substituiçôes de termos comuns por termos técnicos devem-se, provavelmente, à familiarização destes pelo público-alvo.

$\mathrm{Na}$ apreciação do infográfico, todos os domínios obtiveram nível de concordância de 100\%. A única sugestão de um dos participantes foi a remoção da sigla "CAI" do título "Campo de autoinfusão (CAI)", o qual passou a ser "Campo de autoinfusão". 
Em relação às limitações do estudo, podemos citar a seleção intencional por conveniência, feita pela pesquisadora, em relação ao local e ao público-alvo, o que promove a apreciação dos itens das tecnologias educacionais restritas a aspectos sociais e econômicos de uma única região.

\section{Conclusão}

Este estudo elaborou e avaliou tecnologias educativas, que contribuirão com a prática educativa de enfermagem, tendo em vista que se constituem de ilustrações capazes de auxiliar na aquisição de conhecimentos, por meio de memorização dos cuidados necessários à infusão endovenosa do fator de coagulação, além de padronizar as orientações dadas pelos profissionais de saúde às pessoas com hemofilia. As tecnologias educativas elaboradas, avaliadas e apreciadas neste estudo conferem confiabilidade aos produtos, e os tornam promotores do conhecimento, de adesão ao tratamento e promoção do cuidado, permitindo que as pessoas com hemofilia sejam protagonistas do próprio tratamento, mediante maior autonomia para o desempenho seguro do cuidado. Espera-se que outras pesquisas sejam desenvolvidas, avaliando seus aspectos psíquicos e emocionais durante a infusão domiciliar do fator de coagulação.

\section{Colaborações}

Pacheco CRS, Caniçali Primo C, Fioresi M, Sequeira CAC, Nascimento LCN, Lopes AB e Sipolatti WGR colaboraram com a concepção do estudo, análise e interpretação dos dados, redação do artigo, revisáo crítica relevante do conteúdo intelectual e aprovação da versão final a ser publicada.

\section{Referências}

1. Schrijvers LH, Schuurmans MJ, Fischer K. Promoting self-management and adherence during prophylaxis: evidence-based recommendations for haemophilia professionals. Haemophilia. 2016;22(4):499-506. Review.
2. Lambert T, Benson G, Dolan G, Hermans C, Jiménez-Yuste V, Ljung R, et al. Practical aspects of extended half-life products for the treatment of haemophilia. Ther Adv Hematol. 2018;9(9):295-308. Review.

3. Brasil. Ministério da Saúde. Secretaria de Atenção à Saúde. Manual de Hemofilia. Brasília (DF): Ministério da Saúde; 2015 [citado 2019 Maio 27]. Disponível em: http://bvsms.saude.gov.br/bvs/publicacoes/ manual_hemofilia_2ed.pdf

4. Boadas A, Ozelo MC, Solano M, Berges A, Ruiz-Saez A, Linares A, et al. Haemophilia care in Latin America: Assessment and perspectives. Haemophilia. 2018;24(6):e395-e401.

5. Srivastava A, Brewer AK, Mauser-Bunschoten EP, Key NS, Kitchen S, Llinas A, Ludlam CA, Mahlangu JN, Mulder K, Poon MC, Street A; Treatment Guidelines Working Group on Behalf of The World Federation Of Hemophilia. Guidelines for the management of hemophilia. Haemophilia. 2013;19(1):e1-47.

6. Meeks SL, Leissinger CA. The evolution of factor Vlla in the treatment of bleeding in haemophilia with inhibitors. Haemophilia. 2019;25(6):911-8. Review.

7. Barry DG, Hibner S. Care of the chronically ill patient with a bleeding disorder. Rehabil Nurs. 2015;40(3):197-206. Review.

8. Berardinelli LM, Guedes NA, Ramos JP, Silva MG. Tecnologia educacional como estratégia de empoderamento de pessoas com enfermidades crônicas. Rev Enferm UERJ. 2014;22(5):603-9.

9. Santaella ME, Bloomberg MC, Anglade D. National home infusion teaching guidelines will improve quality of care and patient outcomes in haemophilia treatment centres across the USA. Haemophilia. 2017 Jun 21. doi: 10.1111/hae.13289. Epub ahead of print.

10. Oyesiku JO. Home treatment of haemophilia patients with inhibitors. Haemophilia. 2011;17(2):173-8. Review.

11. Gonçalves MS, Celedônio RF, Targino MB, Albuquerque T0, Flauzino PA, Bezerra AN, et al. Development and validation o fan educational booklet for health eating promoting among diabectic patients. Rev Bras Promoç Saúde. 2019;32:7781.

12. Brasil. Ministério da Saúde. Secretaria de Atenção à Saúde. Manual de dose domiciliar para tratamento das coagulopatias hereditárias. Brasília (DF): Ministério da Saúde; 2007 [citado 2019 Maio 27]. Disponível em: http://bvsms.saude.gov.br/bvs/publicacoes/07_0312_M.pdf

13. Brasil. Ministério da Saúde. Agência Nacional de Vigilância Sanitária. Medidas de Prevenção de Infecção Relacionada à Assistência à Saúde. Brasília (DF): Ministério da Saúde; 2017 [citado 2019 Maio 27]. Disponível em: http://portal.anvisa.gov.br/documents/33852/3507912/ Caderno+4+-+Medidas+de+Preven\%C3\%A7\%C3\%A30+de+Infec\%C 3\%A7\%C3\%A30+Relacionada+\%C3\%A0+Assist\%C3\%AAncia+\%C3\% A0+Sa\%C3\%BAde/a3f23dfb-2c54-4e64-881c-fccf9220c373

14. Moreira MF, Nóbrega MM, Silva MI. Comunicação escrita: contribuição para a elaboração de material educativo em saúde. Rev Bras Enferm. 2003;56(2):184-8.

15. Echer IC. Elaboração de manuais de orientação para o cuidado em saúde. Rev Lat Am Enfermagem. 2005;13(5):754-7.

16. Deatrick D, Aalberg J, Cawley J. A Guide to creating and evaluating patient materials. Guidelines for effective print communication. EUA: MaineHealth; 2010 [cited 2019 May 27]. Available from: http://www.mainehealth.org/ workfiles/MH_LRC/MH_Print\%20Guidelines_Intranet.pdf

17. Carvalho J, Aragão I. Infografia: conceito e prática. Rev Bras Design Inform. 2012;9(3):160-77.

18. Alexandre NM, Coluci MZ. Validade de conteúdo nos processos de construção e adaptação de instrumentos de medidas. Cien Saude Colet. 2011;16(7):3061-8. Review. 
19. Pereira RD, Alvim NA. Delphi technique in dialogue with nurses on acupuncture as a proposed nursing intervention. Esc Anna Nery. 2015;19(1):174-80

20. Costa BR. V Bola de neve virtual: 0 uso das redes sociais virtuais no processo de coleta de dados de uma pesquisa científica. Rev Interdisc Gestão Social. 2018;7(1):15-37.

21. Leite SS, Áfio AC, Carvalho LV, Silva JM, Almeida PC, Pagliuca LM. Construction and validation of an Educational Content Validation Instrument in Health. Rev Bras Enferm. 2018;71(4):1635-41.

22. Crestani AH, Moraes AB, Souza AP. Content validation: clarity/relevance, reliability and internal consistency of enunciative signs of language acquisition. CoDAS. 2017;29(4):e20160180.

23. Costa PB, Chagas AC, Joventino ES, Dodt RC, Oriá MO, Ximenes LB. Development and a validation of educational manual for the promotion of breastfeeding. Rev Rene. 2013;14(6):1160-7.

24. Moura $\mathbb{H}$, Silva AF, Rocha AE, Lima LH, Moreira TM, Silva AR. Construction and validation of educational materials for the prevention of metabolic syndrome in adolescents. Rev Lat Am Enfermagem. 2017;25:e2934.
25. Ximenes MA, Fontenele NA, Bastos IB, Macêdo TS, Neto NM, Caetano $J A ́$, et al. Construction and validation of educational booklet contente for all prevention in hospitals. Acta Paul Enferm. 2019;32(4):433-41.

26. Lima AC, Bezerra KC, Sousa DM, Rocha JF, Oriá MO. Development and validation of a booklet for prevention of vertical HIV transmission. Acta Paul Enferm. 2017;30(2):181-9.

27. Moura JR, Silva KC, Rocha AE, Santos SD, Amorim TR, Silva AR. Construction and validation of a booklet to prevent overweight in adolescents. Acta Paul Enferm. 2019;32(4):365-73.

28. Neto NM, Caetano JA, Barros LM, Silva TM, Vasconcelos EM. First aid in schools: construction and validation of na educational booklet for teachers. Acta Paul Enferm. 2017;30(1):87-93.

29. Canadian Hemophilia Society. Home care: the road to independence. Passport to well-being: empowering people with bleeding disorders to maximize their quality of life. Quebec: Canadian Hemophilia Society; 2012. 2nd ed. [cited 2019 May 27]. Available from: https://www.hemophilia.ca/ files/Home\%20care\%20-\%20The\%20road\%20to\%20independence.pdf

30. Shaw D, Riley GA. The impact on parents of developments in the care of children with bleeding disorders. Haemophilia. 2008;14:65-67. 